\title{
Destination morphology: A new framework to understand tourism transport issues?
}

\author{
Gui Lohmann ${ }^{(*)}$ \\ g.lohmann@griffith.edu.au \\ Senior Lecturer in Aviation Management \\ Griffith Aviation, School of Natural Sciences \\ Griffith Institute for Tourism (GIFT), Griffith University \\ 170 Kessels Road, N.25 (Science 1 Building), Nathan, 4111, QLD Australia \\ David Timothy Duval \\ david@dtduval.com \\ Associate Professor \\ Faculty of Business and Economics \\ The University of Winnipeg \\ 515 Portage Avenue \\ Winnipeg, MB Canada \\ R3B 2E9 \\ ${ }^{(*)}$ Corresponding author
}

\section{Introduction and overview}

The role of transport in tourism has almost always been inherently symbiotic and, perhaps more specifically, co-dependent (Hall, 1999). It is critical, therefore, that the attention of governments and policy-makers is directed toward both simultaneously. The parallels between tourism and transport can be characterised as follows:

- Regulatory synergies: Tourism occupies regulatory space(s) that incorporate provisions of safety, environment, and economic contribution. The regulation of one, particularly in the case of transport, can have a meaningful and direct impact on the other. For instance, a successful, targeted tourism marketing campaign can foster increased competition for transport. Similarly, new airline business models can render previously cost-inefficient destinations more attractive (Lohmann \& Duval, 2011). For road transport, regulations affecting the use of a tourists' home driver's license can severely curtain self-drive destinations (see Prideaux \& Carson, 2003). 
- Objective function: Both transport and tourism largely involve personal mobility, albeit with different end results. Tourism provides experiences and value. This, in turn, means movement at different scales, using varying modes of transport which also seek to provide experience and value. Both seek to increase market share by selling differentiation in their products and experiences to key market segments: destinations target specific types of travelers seeking particular experiences; transport providers build fare structures and on-board amenities that hopefully match the expectations of key market segments.

- Shared emphasis on sustainability: Both transport and tourism have been fundamentally transformed in recent years by the drive toward sustainable operations and a reduced footprint (Gossling et al., 2002; Peeters, Szimba \& Duijnisveld, 2007), and both have questioned future development prospects if and when constraints are established to mitigate emissions and other negative externalities (Lohmann \& Duval, 2011; Peeters \& Dubois 2010). This includes shaping user (i.e. tourist) behaviour (Barr et al., 2010; Cohen, Higham, Peeters \& Gössling, 2014; Dallen, 2007). Beyond the mere environmental aspect of sustainability, transport operations in various modes of transport can be challenging also in regards to social, economic and cultural perspectives. These can be particularly significant in very remote parts of the world, as Lohmann and Nguyen (2011) showcase for Hawai'i.

The transport/tourism nexus is arguably not understood well enough in order to model mutual impacts with confidence. A number of aspects can explain this disconnection. First, in many instances tourists are just one of the many types of travelers seeking mobility: one example being public transport in a large metropolis. Most urban transport providers focus on providing transport services to the local population and daily commuters, not necessarily perceiving tourists as their major market. Secondly, displacement of tourists involves several geographical scales, ranging from long-haul trips between places to displacements within destinations. Typically, tourism and transport management organizations and policymakers seldom cover all geographical locations during a travelers' trip; highlighting the challenges inherent to implementing and enforcing transport policies that will be consistent throughout the whole journey. Thirdly, differences in destination geomorphology, concentration of attractions, seasonality of visits, and the nature of the environment can influence the choice of modes of transport and its viability.

This special issue arises from the recognition of the need to maintain focus on further disentangling the relationship(s) between tourism destinations and transport. It remains, despite strong and illuminating contributions over the past few decades, a comparatively understudied topic in either field. We start by offering 
a simple framework based on geomorphology for clarifying how tourism and transport issues might manifest themselves and be characterised. We then outline the contributions in this special issue before concluding with questions of next steps.

\section{Toward a (bounded) geomorphological framework}

While there are several ways of trying to understand the relationship between tourism destinations and transport provision, destination morphologies provide a framework that takes into consideration the geomorphological characteristics of different types of destinations, particularly in regards to demand dispersal, attraction sprawlness, centrality and peripherality in regards to markets for public transport provision and the type of activities undertaken by visitors. Despite the potential for destination morphologies to impact on transport provision, travelers' behaviour and accessibility, a framework dealing with these issues is still lacking in the literature. This paper deals with these matters, aiming to learn what has been presented in the literature by proposing three main morphological types (i.e. urban; islands and archipelagos; rural and mountain destinations).

\subsection{Urban environment}

It is generally acknowledged that urban destinations play a significant role in tourist travel, as in many cases they serve as the point of entry, or gateways, for tourists into the country or region, as centers of accommodation and as bases for excursions to rural areas, in addition to being destinations in their own right (Page \& Hall, 2003). Hence, cities have their own challenges to address tourism mobility, not only within their boundaries (Albalate \& Bel, 2010), but also with regard to visitors en-route to other destinations (Lohmann \& Pearce, 2010, 2012). Marketing and adequate promotion are also critical.

Considering the concentration of population and the current trend of growth of cities, sustainable urban transport measures have become extremely relevant, with a number of initiatives and policies currently implemented in megalopolises around the world (e.g. London, Singapore, São Paulo). Such initiatives include promoting the use of public transport; rejuvenation of central business districts; change in land use in order to provide closer proximity to everyday facilities; accessibility restriction to the central business district; pedestrianisation and weekday banning of cars; and technology innovation, including the decrease in the need for travel or electronic tolls (Banister, 2008; Aftabuzzaman \& Mazloumi, 2011). 
Successful public-transport provision for leisure and tourism demand presents a number of challenges. Gronau and Kagermeier (2007) demonstrate that there are some relevant conditions from the supply side that can contribute to achieve successful public transport services. These include:

- Quality of the public transport service: among several attributes, homogeneous quality service across the whole transport network is fundamental to encourage the use of public transport, particularly in terms of frequency. Data collected in four different leisure parks found empirical evidence to link increased use of public transport with increased frequency of provision;

- Constraints on private cars: measures such as charging for parking had an increase in public transport by $5 \%$ in Zoo Hellabrunn, while restricting car access at certain hours of the day at the Bavarian Forest National Park, when buses run on natural gas were available, was success as a means of increasing public-transport patronage;

- Symbiotic co-operation between leisure facilities and transport providers: combined tickets including the entrance fee to an attraction or leisure facility and public transport have proven successful in inducing the use of public transport among travelers with a private car availability in studies conducted both in Munich (Gronau \& Kagermeier 2007) and Greater Manchester (Lumsdon, Downward \& Rhoden, 2006);

- Long-term effects of transport implementation: as leisure and tourism travelers are not everyday users, it takes a while before public-transport options are widely recognized as suitable alternatives. Promoting new public-transport options can be challenging and it should not be expected that overwhelming success will be achieved in the first season. The examples of bicycle tourists in two low mountain ranges in Germany show that only in the third and fourth seasons was the maximum level of demand for public transport achieved (Gronau \& Kagermeier, 2007). This echoes the results obtained by Dickinson and Dickinson (2006) in the UK.

In terms of non-motorized options for displacement, a number of cities around the world have invested in the establishment of extensive bikeway networks and encouraged commuters to walk. In a study analyzing the connection between built environment and non-motorized transport in Bogotá, the capital city of Colombia (in South America), Cervero Sarmiento et al. (2009) focused particularly on walking and cycling for utilitarian purposes, but also analyzed the use of the reserved Ciclovía lanes for recreational-leisure activities. Aspects found to favour nonmotorized trips were lower-than-average journey length and avoidance of 
congestion with public transport, when private cars have a lower average speed than walking and cycling. On the other hand, some factors that inhibited the walk and biking options included rainy seasons, air pollution, lifestyle and obesity, lower income, concerns over traffic safety, urban design, topography and ultimately the city's elevation which makes physical exercise more tiring.

\subsection{Islands and archipelagos}

In spite of the differences with regard to size, shape and distance to the continental mainland, islands are heavily dependent on transport. Nations and sub-national island entities can be remote, relying on air and maritime transportation to connect them to other regions. The size and development of tourism in an insular environment, in addition to the means of transport to access them, have an impact on how tourists choose their means of transport.

Lohmann and Nguyen (2011) analyze several attempts to establish new air transport routes between the Hawai'ian islands and its major external markets (i.e. mainland US and Japan), as well as inter-island air transport routes. Fierce competition, fuel price increases and the global financial crisis were the major reasons for the failure of a long-established airlines (i.e. Aloha Airlines) and the merger between recently established airlines (i.e. Mokulele and go! airlines) which occurred in the second half of the 2000s. Mergers and acquisitions raise concerns over competition and accessibility, which in island environments can be crucial (e.g. Luis, 2004). Provision of airlift along thin island routes can, however, be questionable from a business perspective and involves substantial risks (Minato \& Morimoto, 2011). It is for this reason that island states must often struggle against their geographic handicaps (Armstrong \& Read, 2006) and find way to ensuring adequate inter- and intra-destination tourist mobilities.

\subsection{Mountainous and rural areas}

Rural areas are difficult to classify precisely. Nevertheless, a number of features which help define such destinations include its scale (small), traditional character in terms of heritage, culture, practices and lifestyles, open space and connection to the natural world (Lane, 1993). There are a number of characteristics particular to mountain and rural tourism environments that affect sustainable transport choices. First, tourists traveling to these places often participate in recreational activities that require the transportation of bulky items and equipment (for example dinghies, canoes, skis, climbing gear, picnics, barbecues etc.) Second, many of these destinations are isolated from public-transport routes, much of which is spatially dispersed (see Butler, Hall, \& Jenkins, 1998). Third, these areas can be prone to seasonality, for example relying on winter tourism in mountainous regions such as 
the Alps (Becken \& Hay, 2007), while more lowland areas such as the Lake District in the UK, may see peaks in visitation during the summer months. Finally, as Prideaux (2009: 219) identifies, mountain regions have "arbitrary political boundaries [which] often ignore geographic, cultural and biological boundaries creating management difficulties".

At peak times such as school holidays and public holidays, cars can be a threat to the resources tourism depends on in such areas (Dickinson \& Robbins, 2007): generating air pollution, creating visual and aural intrusion, causing traffic congestion, which can create delays to bus services, and a lack of parking spaces which can lead to parking 'overspill' into inappropriate areas. However, "the decline of public transportation in rural areas... has meant that 'in rural areas cars are more a necessity than in cities" (DoE/MAF 1995: 132, quoted in Hall, 2005).

Dickinson and Dickinson (2006) documented very real issues for the development of alternative transport in rural areas in the UK and outline reasons why schemes may fail. These include:

- Abandonment of schemes, often due to withdrawal of grant aid, and indeed, many rural public-transport routes are not economically sustainable;

- Local opposition to traffic management and lack of support for public transport. This includes concerns about impacts on local businesses and car users considering public transport an unviable alternative;

- Restrictions on car use and parking are difficult to enforce in a dispersed rural area and initiatives take time and experience to develop.

- Some initiatives (e.g. off-road cycling) generate additional car journeys;

- A tendency to react to acute problems with a resulting ad hoc approach, which is not strategically thought through. For example, the development of cycleways on disused railways is a relatively easy development to implement, but these are sometimes not well thought-through strategically in terms of connectivity.

All this resonates with the findings of the ATKINS study (2005) of Integrated Transport in National Parks (UK), which find barriers to implementation due to the differing priorities facing National Park and local authority; the cost of rural transport provision; and limited revenue funding for transport. In Germany, based on research in the Herz mountains, Hoenninger (2003) points to one of the key issues of public transport use in rural areas for recreational purposes: that of confidence and perceptions of reliability. As a result of concerns that leisure visitors 
may be 'stranded' at the rural destination, backup options such as taxis need to be in place. In more general terms there are costs associated with transport modes of any kind: financial, comfort and time. However, as Lumsdon et al. (2006) observe, the time penalties associated with public transport may not necessarily apply to the discretionary travel market, particularly in a rural environment where taking in the scenery is part of the experience. A number of other studies have also explored transport issues at national parks (Daigle \& Zimmerman, 2004; Downward \& Lumsdon, 2004).

From the above it can be seen that there are a combination of critical factors of success in the rural environment. These include strong partnership working; viable alternatives which are easy to access and understand, and enjoyable to use; integration both for connecting routes and for ticketing; and financial sustainability. Any successful rural transport initiative for tourism will need to consider all these aspects.

\section{About the special issue}

The articles in this special issue bring forward important topics in the area transport and tourism destinations and help to unpack the complexity, yet at the same time reinforce the relationship. The basis of the discussion presented in this special edition is that the varying modes of transport that have a codependent relationship within destinations, and the wider social and economic benefits derived from tourism and transport, all play a major role for how destinations are managed and planned. In particular, most of them contribute to a better understanding of transport in specific destination morphologies.

In their paper, Diem-Trinh Le-Klahn, Regine Gerike and Michael Hall investigate the use of public transport by visitors in the context of an urban destination, Munich, situating their discussion in the broader context of public transport use in general. Importantly, their work suggests that destination marketing organisations need to ensure that public transport options are presented to visitors pre-trip. Christine Currie and Peter Falconer, in contrast, tackle the complex relationship of transport and tourism in the management of island destinations. Islands represent interesting and bounded environments in which policy and planning take place, and their paper showcases some necessary variables in destination co-management strategies involving transport.

Kristian Hvass, meanwhile, touches on the vexed problem of ensuring that destinations are connected to wider air networks. His Danish example is one of indirect subsidisation, and his case illustrates how destinations can assist with 
ensuring the operational and commercial reasons for an airline to serve a destination. Jo Guiver and Davina Stanford's paper develops a best-practices inventory for ensuring the localised planning for visitor travel is parallel in purpose and focus. Their experience points to difficulties in achieving this, but suggest that doing so can help minimise environmental impacts and generate positive social and economic returns. As they note, "travel planning within the destination appears to provide a win-win situation, benefitting most stakeholders, including the local environment."

The paper by Antonio Laurino looks closely at how low-cost carriers utilise secondary airports in Italy. His work is important in that it captures the entrepreneurial business model of many airports as they work to attract airlines and passengers. This has obvious benefits for local tourism: as Laurino notes the policies of locally-owned airports opting for these types of strategies need to be carefully embedded within wider economic-development objectives. The regional spotlight in this issue offers Jill Fjelstul's analysis of the timely issue of sustainable energy use. Focusing on two examples in Orlando, her work shows how the electrification of vehicles for tourist use contributes toward destination sustainability.

\section{Conclusion}

What next for unpacking the tourism/transportation interrelationship? It is encouraging to see that in recent years, national tourism strategies (e.g. the 2015 New Zealand Tourism Strategy) have included considerations of airlift and internal mobility of tourists. Similarly, some national transport (as opposed to transit) strategies (such as Scotland's 2006 National Transport Strategy) have recognised the contribution of tourism. Inadvertent attention devoted exclusively to one has the potential for lopsided or inefficient developments within, for or of the other. The consequence is under-optimized economic returns from a sector (tourism) that still represents one of the most significant exports for many countries. Thus, and at the risk of overstating the obvious, both occupy critical positions in any destination's economy. We also invite readers of this special issue to look at the contributions some of these papers make to understand the transport-destination interface from the perspective of the various destination morphology.

\section{References}

Albalate, D. \& Bel, G. (2010). Tourism and urban public transport: Holding demand pressure under supply constraints. Tourism Management, 31(3), 425-433. 
Aftabuzzaman, M. \& Mazloumi, E. (2011). Achieving sustainable urban transport mobility in post peak oil era. Transport Policy, 18 (5), 695-702.

Armstrong, H \& Read, R. (2006). Geographical 'handicaps' and small states: Some implications for the Pacific from a global perspective. Asia Pacific Viewpoint, 47(1), 79-92.

ATKINS (2005). Integrated transport in National Parks - study report. UK Department for Transport: London.

Banister, D. (2008). The sustainable mobility paradigm. Transport Policy, 15 (2), 73-80.

Barr, S., Shaw, G., Coles, T. \& Prillwitz, J. (2010). 'A holiday is a holiday': Practicing sustainability, home and away. Journal of Transport Geography, 18 (3), 474-481.

Becken, S. \& Hay, J.E. (2007). Tourism and Climate Change: Risks and Opportunities. Channel View, Clevedon.

Butler, R., Hall, C.M. \& Jenkins, J. (eds) (1998). Tourism and Recreation in Rural Areas. John Wiley, Chichester.

Cervero, R., Sarmiento, O.L., Jacoby, E. Gomez, L.F. \& Neiman, A. (2009). Influences of built environments on walking and cycling: lessons from Bogotá. International Journal of Sustainable Transportation, 3(4), 203-226.

Cohen, S., Higham, J., Peeters, P. \& Gössling, S. (eds) (2014). Understanding and Governing Sustainable Tourism Mobility: Psychological and Behavioural Approaches. Routledge, Abingdon.

Daigle, J.J. \& Zimmerman, C. A. (2004). The convergence of transportation, information technology, and visitor experience at Acadia National Park. Journal of Travel Research, 43(2), 151-160.

Dallen, J. (2007). The challenges of diverse visitor perceptions: Rail policy and sustainable transport at the resort destination. Journal of Transport Geography, 15 (2), 104-115. 
Dickinson, J.E. \& Dickinson, J.A. (2006). Local transport and social representations: Challenging the assumptions for sustainable tourism. Journal of Sustainable Tourism, 14(2), 192-208.

Dickinson, J. E. \& Robbins, D. (2007). Using the car in a fragile rural tourist destination: A social representations perspective. Journal of Transport Geography, 15(2), 116-126.

Downward, P. \& Lumsdon, L. (2004). Tourism transport and visitor spending: A study in the North York Moors, National Park, UK. Journal of Travel Research, 42(4), 415-420.

Gössling, S., Hansson, C.B., Horstmeier, O. \& Saggel, S. (2002) Ecological footprint analysis as a tool to assess tourism sustainability. Ecological Economics, 43, 199211.

Gronau, W. \& A. Kagermeier. (2007). Key factors for successful leisure and tourism public transport provision. Journal of Transport Geography, 15(2), 127-135.

Hall, D. (1999). Conceptualising tourism transport: inequality and externality issues. Journal of Transport Geography, 7, 181-188.

Hall, M. (2005). Tourism: rethinking the social science of mobility. Prentice Hall, Don Hills, Ontario.

Hoenninger, P. (2003). MobiHarz project: Integrated mobility management and services for visitors. In ECOMM Managing Transport Demand to Attain Sustainable Transport Demand and Economic Effectiveness - Why and How? Karlstad, 21-23 May.

Lohmann, G. \& Duval, D.T. (2011). Critical aspects of the tourism-transport relationship. In Cooper, C (ed), Contemporary Tourism Reviews. Goodfellow Publishers: Oxford.

Lohmann, G. \& Pearce, D.G. (2010). Conceptualizing and operationalizing nodal tourism functions. Journal of Transport Geography, 18(2), 266-275.

Lohmann, G. \& Pearce, D.G. (2012). Tourism and transport relationships: The suppliers' perspective in gateway destinations in New Zealand. Asia Pacific Journal of Tourism Research, 17(1), 14-29. 
Lohmann, G, \& Nguyen, D.N. (2011). Sustainable tourism transportation in Hawai'i: A holistic approach. In Carlsen, J., \& Butler, R. (eds) Island Tourism Development: Journeys Toward Sustainability. CABI: Wallingford, pp. 197-214.

Luis, J.A.H. (2004). The role of inter-island air transport in the Canary Islands. Journal of Air Transport Management, 12, 235-244.

Lumsdon, L., Downward, P. \& Rhoden, S. (2006). Transport for tourism: Can public transport encourage a modal shift in the day visitor market? Journal of Sustainable Tourism, 14(2), 139-156.

Minato, N. \& Morimoto, R. (2011). Sustainable airline strategy using portfolio theory: A case study of remote islands in Japan. Journal of Air Transport Management, 17, 195-198.

Page, S. \& Hall, C.M. (2003). Managing Urban Tourism. Prentice Hall, Essex.

Peeters, P., Szimba, E. \& Duijnisveld, M. (2007). Major environmental impacts of European tourist transport. Journal of Transport Geography, 15(2), 83-93.

Peeters, P. \& Dubois, G. (2010). Tourism travel under climate change mitigation constraints. Journal of Transport Geography, 18, 447-457.

Prideaux, B. (2009). Resort Destinations: Evolution, Management and Development. Elsevier, Oxford.

Prideaux, B. \& Carson, D. (2003). A framework for increasing understanding of selfdrive tourism markets. Journal of Vacation Marketing, 9(4), 307-313. 